\title{
離散渦法による合流部流れの解析 \\ ANALYSIS OF THE FLOW AT A CONFLUENCE BY A DISCRETE VORTEX METHOD
}

\author{
藤 田一郎* · 河 村三 郎** \\ By Ichiro FUJITA and Saburo KOMURA
}

\begin{abstract}
Two-dimensional discrete vortex method is applied to the flow at a confluence. Simulated results for mean and turbulent velocity characteristics together with the size of a recirculating region have a reasonable accuracy compared with open-channel experimental results. Unsteady large scale structure of the flow in the recirculating region including formation and decomposition of vortices is favorably simulated by this method. Generality of model parameters is examined for flows of different hydraulic conditions in a subcritical flow regime.

Keywords: confluence, junction flow, discrete vortex method, separation bubble, simulation method
\end{abstract}

\section{1. まえがき}

開水路合流部においては支川からの流れが剝離，およ び再付着し，1つの再循環領域（死水域）を形成する. この再循環領域は数多くの剝離渦で構成され, 剝離渦同 士の相互作用によって大規模な渦運動を伴う非定常な変 動特性を示すことが知られている1). 再循環領域の存在 は洪水の疎通能力を低下させる点で問題であり，また， この領域が呈する非定常特性の解明は合流部下流におけ る乱流拡散現象を解明するうえで重要と思われる. しか しながら，死水域を伴うこのような合流部の非定常現象 については, 現在の数值解析的手法では取扱いが困難で あり，まだ十分な検討がなされていない.

そこで, 本研究では, 非定常剝離流れの解析法の 1 つ である離散渦法（渦系近似法）を用いて合流部の流れの シミュレーションを行った. 離散渦法は完全流体中に配 置された多数の渦系によって流れをシミュレートする手 法であり，高レイノルズ数における剝離を伴う非定常流 れの解析に有効である ${ }^{2 \nmid 4)}$. ただし，この手法はあくま でも 1 つのシミレーション手法であり, 流れの基礎方

\footnotetext{
* 正会員 工修 岐阜大学講師 工業短期大学部土木工学科 ( テ501-11 岐阜市柳戸 1-1)

** 正会員 工博 岐阜大学教授 工学部土木工学科 (同上)
}

程式に立脚したものではないため，モデルで使用するパ ラメーターの決定は実験值との比較によらざるを得ず, 場合によっては数多くの試行錯誤によってパラメー夕一 の最適値を決定しなければならないという久点を有す る. 本研究ではまず, 実験值との比較によって最適パラ メーターを決定し, 合流部流れに対する離散渦法の適用 の可能性について検討する.また, 得られた最適パラメー ターを用いて異なる水理条件のときの流れの予測を行 い, 最適パラメーターの普遍性についての検討を行う.

\section{2. 離散渦法によるモデル化}

\section{（1）渦糸の運動方程式}

二次元の完全流体においては渦度 $\omega$ と流れ関数の $\psi$ の間には次式が成立する。

$$
\omega=-\Delta \psi
$$

式（1）の解は

$$
\psi=-\frac{1}{2 \pi} \iint \omega_{0} \log R d S
$$

で与えられる5).ここに, $\omega_{0}$ : 点 $\left(x_{0}, y_{0}\right)$ における渦度, $R$ : 点 $\left(x_{0}, y_{0}\right)$ から任意の点 $(x, y)$ までの距離, $d S$ $=d x_{0} d y_{0}$. いま, $N$ 個の集中渦による渦系の存在する 場を考えると

$$
\omega=\sum_{i=1}^{N} \Gamma_{i} \delta\left[z-z_{i}\right]
$$


と表わすことができる.ここに， $\Gamma_{i}$ は $i$ 番目の渦糸の 循環， $z_{i}$ は $i$ 番目の渦系の座標， $\delta$ は二次元の Dirac のデル夕関数である. 式（3）を式（2）に代入すると

$$
\begin{aligned}
\psi & =-\frac{1}{2 \pi} \sum_{i=1}^{N} \Gamma_{i} \delta\left[z-z_{i}\right] \log R d S \\
& =-\frac{1}{2 \pi} \sum_{i=1}^{N} \Gamma_{i} \log R_{i} \ldots \ldots \ldots \ldots \ldots \ldots . .
\end{aligned}
$$

と表わせる.ここに， $R_{i}$ は $i$ 番目の渦系中心から任意 座標までの距離を示す.これは， $z=z_{i}$ に存在する渦系 の複素速度ポテンシャル

$$
W(z)=\frac{\Gamma_{i}}{2 \pi i} \log \left(z-z_{i}\right)
$$

を $N$ 個重ね合わせた流れ場に相当する.

いま，流れ場の中のある点 $z_{j}\left(=x_{j}+i y_{j}\right)$ に注目す ると, 点 $z_{j}$ に誘起される速度 $u\left(z_{j}\right)=\left(u_{j}, v_{j}\right)$ は式 (4) より,

$$
\begin{aligned}
& u_{j}=\left.\frac{\partial \psi}{\partial y}\right|_{y=y_{j}}=-\frac{1}{2 \pi} \sum_{\substack{i=1 \\
i \neq j}}^{N} \Gamma_{i} \frac{y_{j}-y_{i}}{R_{i j}^{2}} \\
& v_{j}=-\left.\frac{\partial \psi}{\partial x}\right|_{x=x_{j}}=\frac{1}{2 \pi} \sum_{\substack{i=1 \\
i \neq j}}^{N} \Gamma_{i} \frac{x_{j}-x_{i}}{R_{i j}^{2}}
\end{aligned}
$$

で与えられる.ここに，

$$
R_{i j}^{2}=\left(x_{j}-x_{i}\right)^{2}+\left(y_{j}-y_{i}\right)^{2}
$$

である. $i \neq j$ としているのは，渦自身がその存在する 位置 (特異点) に誘起する誘導速度 $(u \rightarrow \infty)$ を除去す るためである6).

いま，点 $z_{j}$ に渦糸が存在するとすれば，その渦糸は 式（6）および, 式（7）で示される誘導速度に従って 運動するものと考えられる。このとき, 渦系の移動速度 $\left(d x_{j} / d t, d y_{j} / d t\right)$ は誘導速度に一致し,

$$
\begin{aligned}
& \frac{d x_{j}}{d t}=u_{j} \\
& \frac{d y_{j}}{d t}=v_{j}
\end{aligned}
$$

となる. 式（9）および，式（10）が渦糸の運動を支配 する方程式である7!. したがって，式 $(6)$ （10）で表 わされる $2 N$ 個の常微分方程式を解けば, 流れの様子 を完全に定めることができる．式（9），(10）を複素表 示すれば

$$
\frac{d \bar{z}_{j}}{d t}=\left.\frac{d W_{j}}{d z}\right|_{z=z_{j}}
$$

となる. $W_{j}$ の添字 $j$ は特異点 $(i=j)$ を除いて総和を とることを示す.

一方, 物理面 $(z)$ 上の現象を

$$
\zeta=f(z)
$$

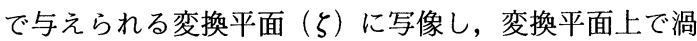
糸の運動を追跡する場合には，運動方程式，式（11）は 次式のように変形される ${ }^{8)}$.

$$
\frac{d \bar{\zeta}_{j}}{d t}=\frac{d W_{j}}{d \zeta} \cdot\left|\frac{d \zeta}{d z}\right|_{\zeta=\zeta_{j}}^{2}
$$

しかしながら，渦糸の運動は物理面上で論じなければ ならないので, $j$ 番目に発生させた渦糸の位置に誘導さ れる速度 $\left\{u_{j}(z), v_{j}(z)\right\}$ は物理面上での渦糸自身の誘 導速度を差し引いて

$$
u_{j}(z)-i v_{j}(z)=\frac{d W_{j}(\zeta)}{d z}-\frac{\Gamma_{j}}{2 \pi i} \cdot \frac{1}{z-z_{j}}
$$

とし， $z \rightarrow z_{j}$ なる極限操作より求めなければならない (Routh's rule). 極限操作の結果のみを示すと次のよ うである ${ }^{9)}$.

$u_{j}(z)-i v_{j}(z)=\frac{d W_{j}(\zeta)}{d \zeta} \cdot \frac{d \zeta}{d z}-\frac{i \Gamma_{j}}{2 \pi} \cdot \frac{f^{\prime \prime}(z)}{2 f^{\prime}(z)}$

$f(z)$ は式 $(12)$ に示した変換関係である.

\section{（2）合流部への適用}

合流水路を Fig. 1，変換平面を Fig. 2 のように定義す ると合流水路の内部領域を変換平面の上半分の領域に変 換する写像関係は，Schwarz-Christoffel の定理より得 られる，

$$
\frac{d z}{d \zeta}=K \frac{\sqrt{\zeta} \sqrt{\zeta-1}}{(\zeta+e)(\zeta-c)}
$$

を積分して次のように求められる。

$$
\begin{aligned}
z= & -\frac{2 B_{3} i}{\pi} \tan ^{-1}\left(\frac{\sqrt{1+e} \sqrt{\zeta}}{\sqrt{e}+\sqrt{1-\zeta}}\right) \\
& -\frac{B_{3} i}{\pi} \log \frac{\sqrt{c-c^{2}} \sqrt{\zeta} / \sqrt{1-\zeta}-c}{\sqrt{c-c^{2}} \sqrt{\zeta} / \sqrt{1-\zeta}+c} \\
& +\frac{2 B_{3} i}{\pi} \cdot \tan ^{-1} \frac{\sqrt{\zeta}}{\sqrt{1-\zeta}}+B_{3} i \cdots \ldots \ldots . .
\end{aligned}
$$

ここに, 写像係数 $c, e$, および水路幅比 $B_{r}\left(=B_{2} / B_{3}\right)$ の間には次のような関係が成立している。

$$
\begin{aligned}
& B_{r}=\frac{\sqrt{c-c^{2}}}{c+e} \cdots \\
& c+e=\sqrt{e+e^{2}} .
\end{aligned}
$$

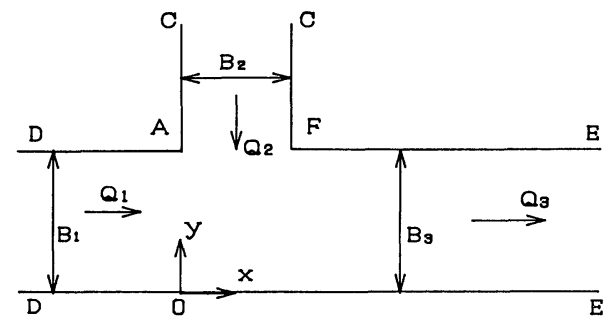

Fig. $1 z$-plane.

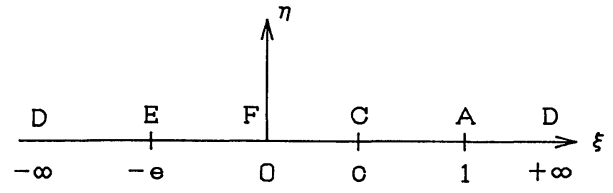

Fig. $2 \zeta$-plane. 
ポテンシャル流は, 変換平面で点 $\mathrm{C}$ に湧き出し, 点 $\mathrm{E}$ に吹込みを置いて表わすことができ,

$$
W_{p}(\zeta)=-\frac{Q_{3}}{\pi} \log (\zeta+e)+\frac{Q_{2}}{\pi} \log (\zeta-c)
$$

で与えられる. また，合流部ではFig. 1 の点 A と点 F か らの渦の発生が考えられるので, 離散渦のみによる複素 速度ポテンシャル $W_{v}(\zeta)$ は,

$$
\begin{aligned}
W_{v}(\zeta)= & -\sum_{i=1}^{N} \frac{i \Gamma_{F i}}{2 \pi} \log \left(\zeta-\zeta_{F i}\right)+\sum_{i=1}^{N} \frac{i \Gamma_{F i}}{2 \pi} \log \left(\zeta-\bar{\zeta}_{F i}\right) \\
& -\sum_{i=1}^{N} \frac{i \Gamma_{A i}}{2 \pi} \log \left(\zeta-\zeta_{A i}\right)+\sum_{i=1}^{N} \frac{i \Gamma_{A i}}{2 \pi} \log \left(\zeta-\bar{\zeta}_{A i}\right)
\end{aligned}
$$

と表わすことができる.ここに，添字 $A, F$ はそれぞれ 点 $\mathrm{A}, \mathrm{F}$ から発生した渦（以後, $\mathrm{A}$ 点渦, $\mathrm{F}$ 点渦と表現 する）に関連する変数を示す. 右辺第 2 項と第 4 項は境 界面が流線となるように配置される鏡像渦の複素速度ポ テンシャルであり, 共役複素数で示される $\bar{\zeta}_{A i}$ および $\bar{\zeta}_{F i}$ は鏡像渦の位置である.

ポテンシャル流と離散渦群の複素速度ポテンシャルを 重ね合わせて全体の流れ場を次式のように表わせば,

$$
W(\zeta)=W_{p}(\zeta)+W_{v}(\zeta)
$$

となる. 渦糸の移動速度は, 式 (15) を用いて以下のよ うに求めることができる.すなわち，点 $\mathrm{A} か ら ~ i$ 番目に 放出された渦糸に対しては

$$
\begin{aligned}
u_{i A}-i v_{i A}= & -\frac{Q_{3}}{\pi\left(\zeta_{i}+e\right)}+\frac{Q_{2}}{\pi\left(\zeta_{i}-c\right)} \\
& -\sum_{\substack{j=1 \\
j \neq i}}^{N} \frac{i \Gamma_{A j}}{2 \pi} \cdot \frac{1}{\left(\zeta_{i}-\zeta_{A j}\right)}+\sum_{j=1}^{N} \frac{i \Gamma_{A j}}{2 \pi} \cdot \frac{1}{\left(\zeta_{i}-\bar{\zeta}_{A j}\right)} \\
& \left.-\sum_{j=1}^{N} \frac{i \Gamma_{F j}}{2 \pi} \cdot \frac{1}{\left(\zeta_{j}-\zeta_{F j}\right)}+\sum_{j=1}^{N} \frac{i \Gamma_{F j}}{2 \pi} \cdot \frac{1}{\left(\zeta_{j}-\bar{\zeta}_{F j}\right)}\right\} \\
& \times\left\{-\frac{\pi\left(\zeta_{i}+e\right)\left(\zeta_{i}-c\right)}{B_{3} \sqrt{\zeta_{i}} \sqrt{\zeta_{i}-1}}\right\}+F\left(\zeta_{i}\right) \cdots \cdots(23)
\end{aligned}
$$

点 $\mathrm{F}$ から $i$ 番目に放出される渦系に対しては,

$$
\begin{aligned}
u_{i F} & -i v_{i F}=\left\{-\frac{Q_{3}}{\pi\left(\zeta_{i}+e\right)}+\frac{Q_{2}}{\pi\left(\zeta_{i}-c\right)}\right. \\
& -\sum_{j=1}^{N} \frac{i \Gamma_{A j}}{2 \pi} \cdot \frac{1}{\left(\zeta_{i}-\zeta_{A j}\right)}+\sum_{j=1}^{N} \frac{i \Gamma_{A j}}{2 \pi} \cdot \frac{1}{\left(\zeta_{i}-\bar{\zeta}_{A j}\right)} \\
& \left.-\sum_{\substack{j=1 \\
j \neq i}}^{N} \frac{i \Gamma_{F j}}{2 \pi} \cdot \frac{1}{\left(\zeta_{i}-\zeta_{F j}\right)}+\sum_{j=1}^{N} \frac{i \Gamma_{F j}}{2 \pi} \cdot \frac{1}{\left(\zeta_{i}-\bar{\zeta}_{A j}\right)}\right\} \\
& \times\left\{-\frac{\pi\left(\zeta_{i}+e\right)\left(\zeta_{i}-c\right)}{B_{3} \sqrt{\zeta_{i}} \sqrt{\zeta_{i}-1}}\right\}+F\left(\zeta_{i}\right) \cdots \ldots \ldots \ldots
\end{aligned}
$$

と表わすことができる.ここに，

$$
\begin{aligned}
F\left(\zeta_{i}\right)= & {\left[i \Gamma_{i}\left(2 \zeta_{i}+e-c\right) \sqrt{\zeta_{i}\left(\zeta_{i}-1\right)}\right.} \\
& \left.-\left\{\zeta_{i}\left(\zeta_{i}-1\right)\right\}^{-1 / 2}\left(\zeta_{i}+e\right)\left(\zeta_{i}-c\right)\left(2 \zeta_{i}-1\right) / 2\right] \\
& \div\left\{4 B_{3} \zeta_{i}\left(\zeta_{i}-1\right)\right\} \ldots \ldots \ldots \ldots \ldots \ldots \ldots \ldots \ldots \ldots \ldots \ldots \ldots \ldots \ldots \ldots \ldots \ldots \ldots
\end{aligned}
$$

以上の関係より， $N$ 個だけ渦が放出された時点にお ける流速は次式より求められる.

$$
\begin{aligned}
u(z) & -i v(z)=\left\{-\frac{Q_{3}}{\pi(\zeta+e)}+\frac{Q_{2}}{\pi(\zeta-c)}\right. \\
& -\sum_{i=1}^{N} \frac{i \Gamma_{F i}}{2 \pi} \cdot \frac{1}{\left(\zeta-\zeta_{F i}\right)}+\sum_{i=1}^{N} \frac{i \Gamma_{F i}}{2 \pi} \cdot \frac{1}{\left(\zeta-\bar{\zeta}_{F i}\right)} \\
& \left.-\sum_{i=1}^{N} \frac{i \Gamma_{A i}}{2 \pi} \cdot \frac{1}{\left(\zeta-\zeta_{A i}\right)}+\sum_{i=1}^{N} \frac{i \Gamma_{A i}}{2 \pi} \cdot \frac{1}{\left(\zeta-\bar{\zeta}_{A i}\right)}\right\} \\
& \times\left\{-\frac{\pi(\zeta+e)(\zeta-c)}{B_{3} \sqrt{\zeta} \sqrt{\zeta-1}}\right\} \ldots \ldots \ldots \ldots \ldots \ldots \ldots \ldots \ldots \ldots \ldots \ldots \ldots
\end{aligned}
$$

\section{（３）渦糸の強さの決定方法}

渦系の強さは基本的には, 点 $\mathrm{A}, \mathrm{F}$ に対してKutta の 条件を適用し，

$$
\begin{aligned}
& \left.\frac{d W}{d \zeta}\right|_{5=5_{A}}=0 \\
& \left.\frac{d W}{d \zeta}\right|_{5=5_{r}}=0
\end{aligned}
$$

を解けば，求めることができるはずであるが，発生渦の 個数が増大してくると, 式 (27)，(28）の解が発散する 場合があったため，次のような手順を用いて安定的に循 環の值が求められるようにした.

a) 点 Aからの発生したばかりの渦（初生渦）の導入 位置を点 $A$ 近傍に固定する，点 F からの初生渦の導入位 置は可変とし, 支川壁 CF の延長線上に任意に定める.

b) 点 Fからの初生渦の強さをまず

$d \Gamma / d t=U_{F}^{2} / 2$

より求める ${ }^{10)}$. 渦系の導入間隔を $d t_{v}$ とすると, 上式は 次のように表わせる.

$\Gamma_{F 1}=U_{F}^{2} / 2 \cdot d t_{v}$

ここに, $U_{F}$ は点 $\mathrm{F}$ からの初生渦の導入位置における流 速の絶対值である.

c) 点 A と点 Fに Kutta の条件を適用し,式(27),(28) を同時に満足するように点 $\mathrm{F}$ に関する初生渦導入位置を 変化させる. 点 $\mathrm{A}$ 側の導入位置は合流する 2 つの流れの 間に生じるせん断層のほぼ中心，点 $\mathrm{F}$ 側の導入位置は剝 離せん断層の外縁近傍に対応するように設定している.

d） c）の解が収束しない場合は点 Fに関する初生渦 導入位置を固定し, 点 AのみにKutta の条件を課する. この場合, 点 Aからの初生渦の強さ $\Gamma_{A 1}$ は式 $(27)$ を用 いて得られた次式より求める.

$$
\begin{aligned}
\frac{i \Gamma_{F 1}}{2 \pi} & \cdot\left\{\frac{-1}{\left(1-\zeta_{F 1}\right)}+\frac{1}{\left(1-\bar{\zeta}_{F 1}\right)}\right\} \\
& +\frac{i \Gamma_{A 1}}{2 \pi} \cdot\left\{\frac{-1}{\left(1-\zeta_{A 1}\right)}+\frac{1}{\left(1-\bar{\zeta}_{A 1}\right)}\right\} \\
= & -\sum_{i=2}^{N} \frac{i \Gamma_{F i}}{2 \pi} \cdot\left\{\frac{-1}{\left(1-\zeta_{F i}\right)}+\frac{1}{\left(1-\bar{\zeta}_{F i}\right)}\right\}
\end{aligned}
$$

である. 


$$
\begin{aligned}
& -\sum_{i=2}^{N} \frac{i \Gamma_{A i}}{2 \pi} \cdot\left\{\frac{-1}{\left(1-\zeta_{A i}\right)}+\frac{1}{\left(1-\bar{\zeta}_{A i}\right)}\right\} \\
& +\frac{Q_{3}}{\pi(1+e)}-\frac{Q_{2}}{\pi(1-c)} \cdots \ldots \ldots \ldots . . .
\end{aligned}
$$

初生渦 $\Gamma_{A 1}, \Gamma_{F 1}$ の導入点の座標を Fig. 3 に示す.

\section{(4) 渦糸の運動方程式の積分}

渦糸の運動は渦糸の運動方程式である式 (13) にオイ ラー法を適用して次式より計算する.

$$
\begin{aligned}
& x(t+d t)=x(t)+u(t) d t \\
& y(t+d t)=y(t)+v(t) d t
\end{aligned}
$$

渦系の導入間隔 $d t_{v}$ と時間ステップ $d t$ の関係は次式 で与える. $K$ は $2 \sim 5$ 程度の整数である.

$$
d t_{v}=K d t
$$

\section{（5）粘性効果の導入}

離散渦法は，そもそも完全流体における非粘性の流れ を対象としているので粘性力を直接導入することはでき ないが, 本研究では渦糸中心の特異性 $(u \rightarrow \infty)$ を除去 するために，渦糸の中心部分 (core) に次式に示すよう な構造を与えることとする (cut-off vortex $)^{10)}$.

$$
\left.\begin{array}{ll}
v_{\theta}=\Gamma /(2 \pi r), & v_{r}=0:(r>\sigma) \\
v_{\theta}=\Gamma /(2 \pi \sigma), & v_{r}=0:(r \leq \sigma)
\end{array}\right\}
$$

Fig. 4 に $v_{\theta}$ の半径方向の分布を示す. Cut-off vortex の導入は渦系 (特異点) の集合である流れ場を式（35） で示されるフィルターを通してみることに相当すると考 えられる. 渦系の強さを時間的に減衰させて粘性効果を 導入することも行われているが10), 本研究では取り入れ ていない. ただし, 以下の基準により渦系の消去は行っ ている.

（a）物体表面 (水路側壁) に, 渦系半径の半分まで 渦糸が接近すれば，その渦を消去する.

（b）剝離点より $x=4 B_{3}$ 以上，流下した渦は消去

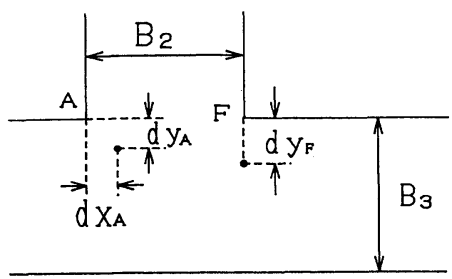

Fig. 3 Nascent vortex points.

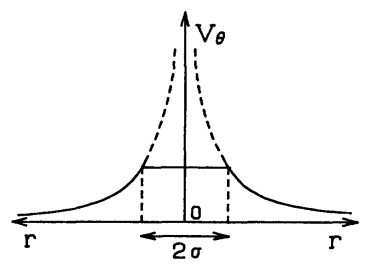

Fig. 4 Cut-off vortex.
する.

\section{(6) 計算手順}

ポテンシャル流を初期状態とし,式(30), または式(31) で循環が与えられる初生渦をそれぞれ点 A, F の近傍の 渦発生点（Fig. 3）に配置する. 初生渦を式 (23)，(24) で求められる誘導速度に従って $d t$ の間移動させる.こ の初生渦の移動を $K$ ステップ繰り返し, 時間が $K d t$ $\left(=d t_{v}\right)$ 経過した時点で新たな初生渦を配置する. 以 上の手順を繰り返し, 渦糸の発生・移動, あるいは消去 を行っていく. 統計的な解析は計算対象領域内での渦系 の個数が一定となった後のデータに対して行う. 計算手 順のフローチャートを Fig. 5 に示す.

\section{3. 実験方法}

解析結果を検証するために開水路を用いた実験を行っ た. 実験水路は本川長約 $10 \mathrm{~m}$, 支川長約 $2.5 \mathrm{~m}$, 本川 幅 $30 \mathrm{~cm}$, 支川幅 $20 \mathrm{~cm}$ で河床勾配は水平である. 水路 幅・水深比は，ほぼ一定に保つようにしている. 流速は 直径 $3 \mathrm{~mm}$ の超小型正逆プロペラ流速計を各測点で主流 方向に向けて測定した. 主流の向きは夕フトを用いて測 定した.ただし, 逆流域では主流の方向は明確には定ま らないので $x$ 軸方向へ固定した. サンプリング周波数 は $10 \mathrm{~Hz}$ とし, 約 60 秒間のデータを用いて統計処理を 行った.

合流部で剝離した支川側壁上の境界層は渦糸群を生成 し, 個々の渦系は流下とともに三次元的に変形していく が, 渦糸は水面とは垂直に交わっているため, 水面近傍 では二次元性をある程度保っていると考えられる.した がって, 本研究では主として水面に近い領域の流況と離 散渦法との比較を行っている. Table 1 に実験条件を示 す. 添字 $1 ， 2 ， 3$ はそれぞれ本川上流（合流点より $2 \mathrm{~m}$ 上流の断面), 支川 (合流点より $1 \mathrm{~m}$ 上流の断面), 本 川下流（合流点より $2 \mathrm{~m}$ 下流の断面）の流れにかかわ

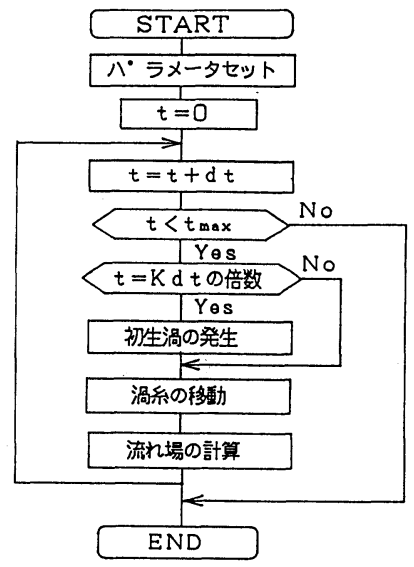

Fig. 5 Flow-chart for computation. 
Table 1 Experimental conditions.

\begin{tabular}{|c|c|c|c|c|c|c|c|c|c|c|c|c|}
\hline RUN & $\mathrm{d}_{3}$ & $Q_{r}$ & $\mathrm{~B}_{3}$ & $\mathrm{~B} 2$ & $\mathrm{H}_{2}$ & $\underset{(\mathrm{S} 2}{\mathrm{Hz}}$ & $\underset{\text { (om }}{\mathrm{H}_{3}}$ & $\mathrm{Um}_{\mathrm{m}}$ & $F_{r_{1}}$ & Fr2 & Fr 3 & $R_{\theta 9}$ \\
\hline $\mathrm{Al}$ & 5.0 & 0.2 & 30.0 & 20.0 & 6.00 & 5,99 & 5,10 & 32.7 & 0.286 & 0.109 & 0,462 & 16700 \\
\hline A2 & 5.0 & 0.4 & 30.0 & 20.0 & B. 29 & 6.19 & 5.13 & 32.5 & 0.202 & 0.208 & 0.458 & 16700 \\
\hline A3 & 5.0 & 0.6 & 30.0 & 20.0 & 6.47 & 6.40 & 5,17 & 32.2 & 0.131 & 0.293 & .452 & 16700 \\
\hline B1 & 2.5 & 0.2 & 30.0 & 20.0 & 5.44 & 5.38 & 5.02 & 16.6 & 0.168 & 0.064 & 0.236 & 8330 \\
\hline $\mathrm{B} 2$ & 2.5 & 0.4 & 30.0 & 20.0 & 5.51 & 5.44 & 5.02 & 16.6 & 0.124 & 0.126 & 0.237 & 8930 \\
\hline B3 & 2.5 & 0.6 & 30,0 & 20,0 & 5,51 & 5,48 & 5.05 & 16.5 & 0.082 & 0.186 & 0.235 & 8330 \\
\hline
\end{tabular}

Table 2 Model parameters.

\begin{tabular}{|c|c|}
\hline$U_{3} d_{t v} / B_{3}$ & 0.0889 \\
\hline$K(=d t v / d t)$ & 2 \\
\hline$\sigma /\left(U_{3} d t v\right)$ & 0.281 \\
\hline$d y_{F} /\left(U_{3} d t v\right)$ & 0.281 \\
\hline$d y_{A} /\left(U_{3} d t_{v}\right)$ & 0.199 \\
\hline$d x_{A} /\left(U_{3} d t_{v}\right)$ & 0.199 \\
\hline
\end{tabular}

る諸量, $U_{m}$ は合流後水路の断面平均流速, $H$ は平均水 深, Fr はフルード数, Re はレイノルズ数を示す.

\section{4. 解析結果}

\section{（1）モデルパラメーターの決定}

モデルパラメーターは cut-off vortex の半径 $\sigma$ 之渦導 入間隔 $d t_{v}$ を種々変化させてシミュレーションを行い, 平均的な逆流域規模と乱れ特性の分布が実験值に最も近 い $\sigma$ と $d t_{v}$ の組合せを求めて決定した. 渦導入位置 $\left(d y_{F}, d x_{A}, d y_{A}\right)$ は壁面から $\sigma$ だけ離れた点として与 えた. 渦系の移動ステップ $K$ は Kiya $~^{10)}$ のモデルを参 照して 2 とおいた．このようにして得られた以上 $6 つ の$ モデルパラメーターを Table 2 に示す. $U_{3}$ は物理面に おける合流後水路の平均流速であり，ここでは断面平均 流速 $U_{m}$ に等しいとした. Fig. 6 には計算対象領域内の 渦糸の個数の変化を示しているが, 計算值は渦系個数が ほぼ定常に達したと考えられる $t U_{3} / B_{3}=22$ より $t U_{3} / B_{3}=44$ までのデー夕から求めている. 渦系の個数 は基本的には時間とともに単調に増大するはずである が, 前述のように渦糸消去の操作を加えているため, あ る程度時間が経過すると, 多少の増減を伴いながらも渦 系発生個数と消去される渦系の個数がバランスし, 安定 な状態に達している，また，いくつかの試算的な解析よ り, 得られた最適パラメーターの中で結果に最も重大な 影響を与えるのは渦系発生間隔 $d t_{v}$, 次に F 点渦の発生 位置 $d y_{F}$ であることがわかった，再循環領域の規模は $d t_{v}$ の増減に伴って拡大・収縮し，また $d y_{F}$ の値によっ ては逆流域そのものが計算されなくなる場合がある。 $\sigma$ の値が小さい場合には乱れ強度等が増大する傾向を示 す.A 点渦の発生位置の違いが計算結果に及ぼす影響 は小さい.

\section{（2）流速分布特性}

Fig. 7 と Fig. 8 に平均流速ベクトル，および乱れ強度

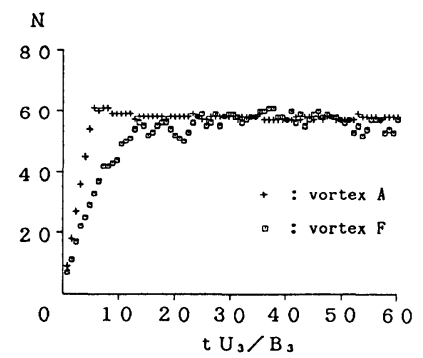

Fig. 6 Number of vortex points.

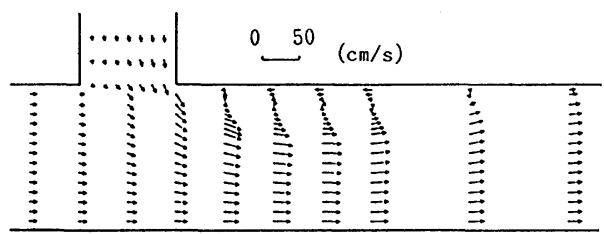

(a) c a l cul a tion

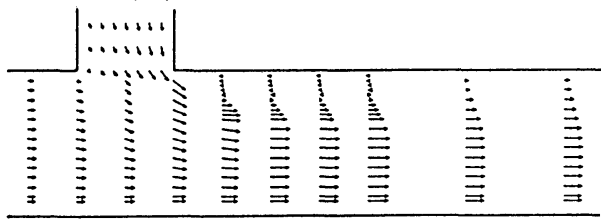

(b) experiment $\quad\left(z / H_{3}=0.9\right)$

Fig. 7 Mean velocity vectors.

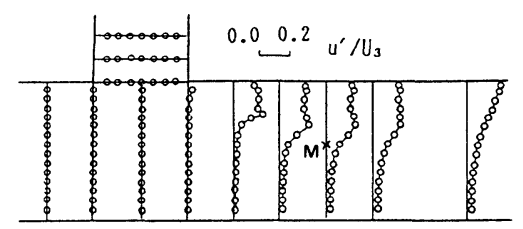

(a) c a lculation

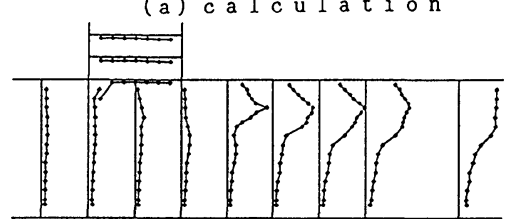

(b) experiment

Fig. 8 Turbulent velocities (Run B 2).

分布を示す. 実験値は相対水深 $z / H_{3}=0.9$ における值 である. 本川と支川上の乱れ強度分布のプロットはそれ ぞれ本川側壁, 支川側壁に沿った方向の成分の分布を示 す. Fig.7 より, 壁面付近の逆流の值は計算值の方が若 干大きいことがわかる．これは壁面近傍での渦糸の消去 だけでは壁面における粘性効果を十分に表わすことがで きず，逆に鏡像渦の影響を受けて渦系の移動速度が増大 したためと考えられる. また，壁面における no slip の 条件を取り入れることができないため, 再付着後の流速 分布には若干の相違がみられる. しかし，全体的な平均 


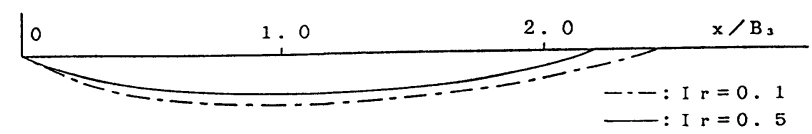

(a) calculation

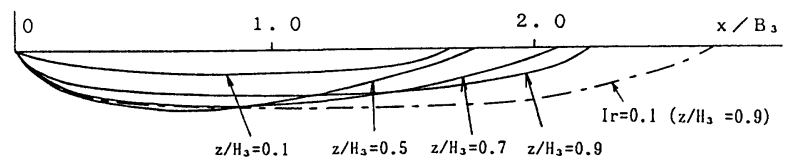

(b) experiment

Fig. 9 Reverse flow ratio (Run B 2).

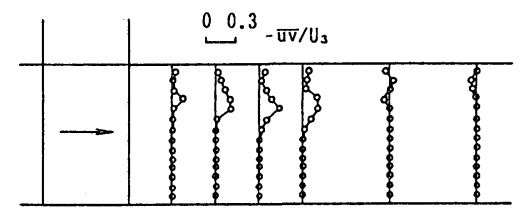

Fig. 10 Distribution of turbulent shear stress (calculation, Run B 2).

流の場は，ほぼ再現できていると考えられる．乱れ強度 の分布は, 特に再循環領域の内部で実験值との相違がみ られる. 測定に用いたプロペラ流速計はプロペラの直径 が $3 \mathrm{~mm}$ 程度の非常に小さなものであるが, 測定可能な 最低流速は $2.5 \mathrm{~cm} / \mathrm{s}$ 程度と有限であり，また流れの向 きが頻繁に順流と逆流を繰り返す場合にはどうしてもプ ロペラ自身の回転の慣性力が無視できない。すなわち， 平均流速が 0 に近づくと計測精度は低下し, 乱れ強度は 実際の值よりも過大に評価されると考えられる．合流前 の流れは, ほぼポテンシャル流に一致しているため, 乱 れ強度は実験值に比べて小さな值を示している．以上の ような点を除けば，Fig. 8 に得られた結果はおおむね良 好な一致を示しているといえる．ただし，再付着後の流 れに関しては実際の剝離渦がほぼ本川流向に平行に流 下・拡散するのに対し, 離散渦法では側壁に向かう流速 成分が誘導されるために，側壁近傍での鏡像渦の影響も 受けて，側壁付近における乱れが増大している．壁面垂 直方向の付加的な移動速度を個々の離散渦に与える試み も行われているが(0), その移動速度を合理的に求めるこ とは困難であるため, 本研究では移動速度の付加は行っ ていない.したがって, 本研究では主に剝離して再付着 するまでの間の流れを対象とすることとする. Fig. 9 は 逆流率 $I_{r}$ の平面的な分布の比較を示したものである. 逆流率は計測時間中に生じた逆流の割合であり, $I_{r}=$ 0.5 は平均流速がほぼ 0 となる位置に対応すると考えら れる. $I_{r}=0.1$ は非定常に摇動する再循環領域の平面的 な摇動範囲の限界にほぼ対応するものと考えられる．実 際の再循環領域は三次元的な構造を有しているが,

Fig. 9 より明らかなように水路床に近い $Z / H_{3}=0.1$ の

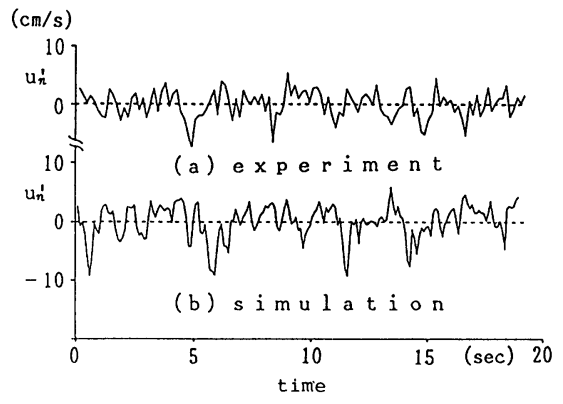

Fig. 11 Comparison of time series of main flow velocity near the edge of a separated flow.

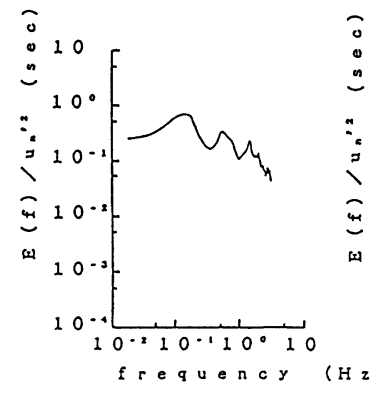

(a) simulation

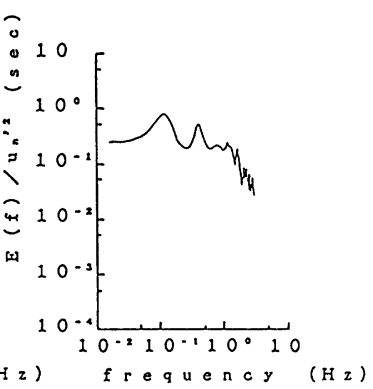

(b) experiment
Fig. 12 Comparison of power spectra.

データを除けば，マクロ的には平面的なものとみなすこ とができる. Fig. 9 より $I_{r}=0.5$ の分布は実験值とほぼ 一致しており, 離散渦の導入によって逆流域が良好に再 現されていることがわかる.一方， $I_{r}=0.1$ を含めた全 体的な再循環領域の規模は, 実験値よりも若干小さい. これは前述のように, 離散渦群全体が有する側壁に向か う誘導速度のためと考えられる. Fig. 10 には, 乱流せ ん断力の計算値を示す. 剝離せん断層に沿う乱流せん断 力の増大が得られていることがわかる.

\section{（3）非定常特性}

Fig. 11 にせん断層外縁付近の測点 (Fig. 8 の点M) に おける流れ方向の流速時系列の一例を示す. $u_{n}^{\prime}$ : 主流 方向の乱れ速度. 実験值はプロペラ流速計によるものな ので高周波成分についての考察はできないが，低周波成 分に限っていえば，離散渦法によって生成された流速時 系列は実際の流れ之類似しているといえる. 周波数変動 特性について検討するために，スペクトルを比較したの が Fig. 12 である.これより剶離せん断層近傍において は，2つの卓越周波数が存在していることがわかる. 低 周波側のピーク（約 $0.1 \mathrm{~Hz}$ ) は再循環領域が伸張・収 縮を繰り返す大規模な渦運動の周波数に対応し, 高周波 側のピーク（約 $0.5 \mathrm{~Hz}$ ）は剝離渦の移動に伴って生じ る流速変動の周波数に対応すると考えられる.このよう な周波数帯における二重構造は計算值においても再現さ 
れており，流れの非定常特性が良好にシミュレートされ ていることがわかる.このような特性は後述の他のケー スについても得られている.

\section{（4）空間的変動特性}

渦糸の運動が安定化した後の渦糸の $d t_{v}$ 間の移動軌
跡を $t=0 \sim 52 d t_{v}$ にわたってプロットしたのが Fig. 13 である．渦糸がいくつかの集合体となってまとまり，合 体・崩壊といった大規模渦運動を行っている様子が再現 されている.たとえば, $t=6 d t_{v}$ では再循環領域は 3 つに分裂しているが, 下流側の渦群は時間経過とともに
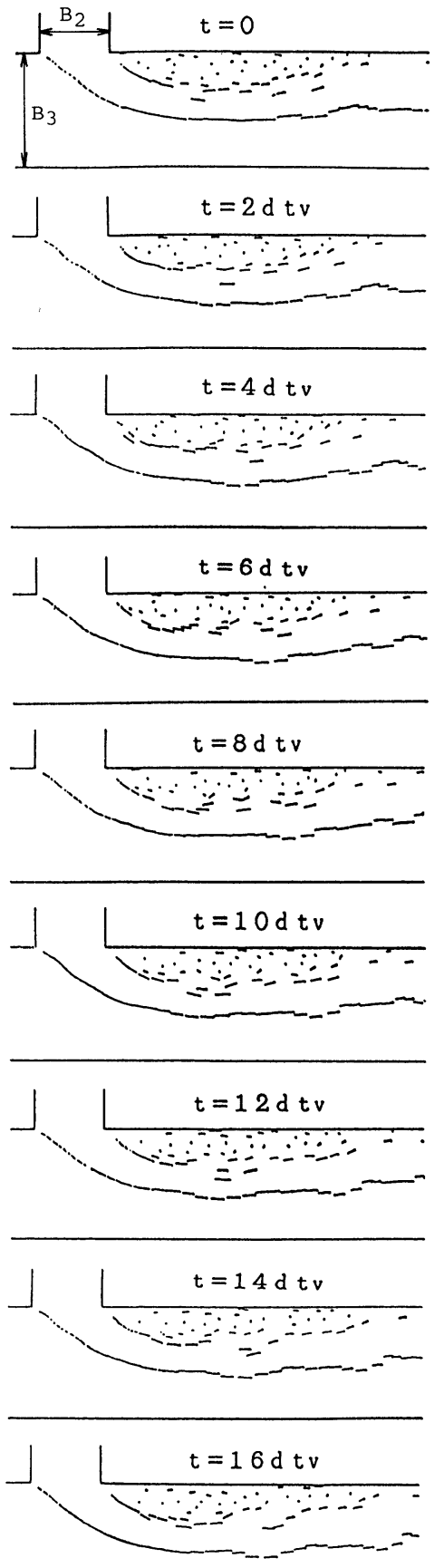
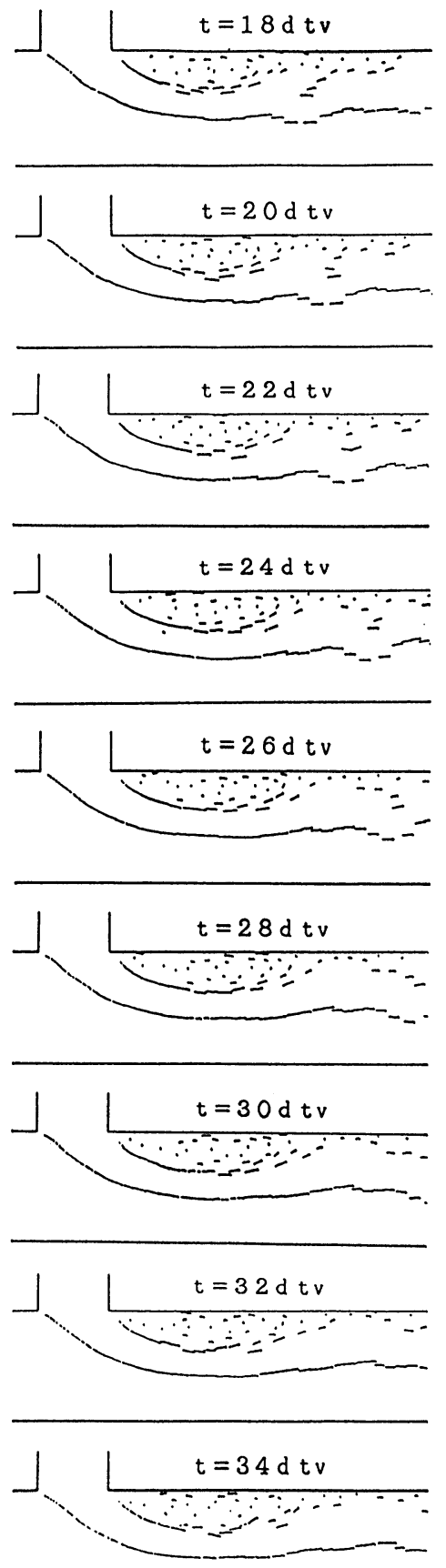
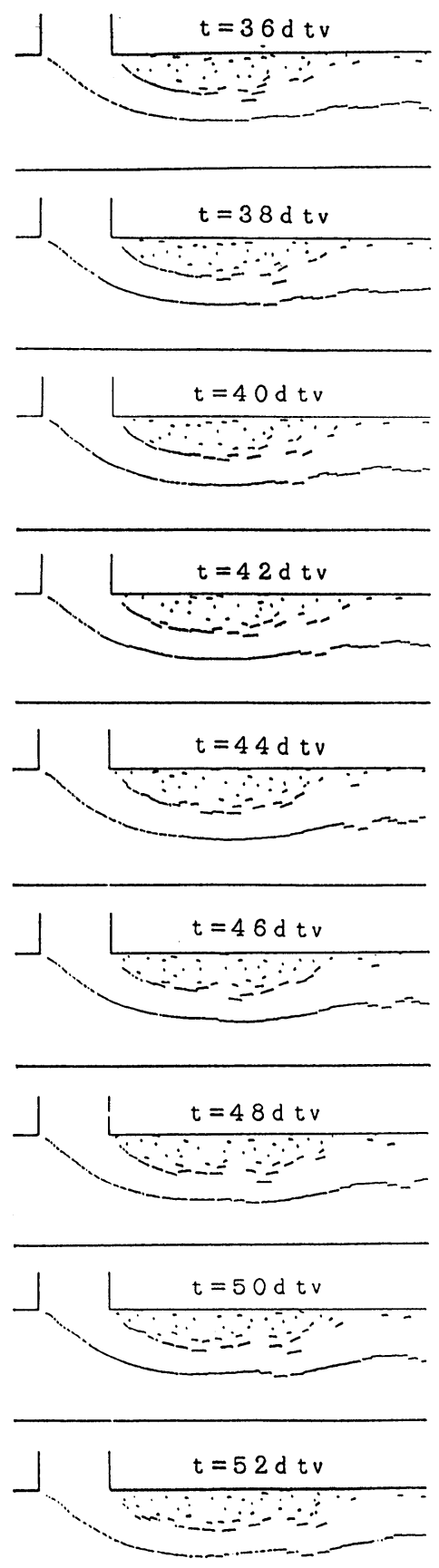

Fig. 13 Calculated process of vortex formation and decomposition (RUN B 2). 
流下し, $t=26 d t_{v}$ において最も収縮した後に膨張しは じめ, $t=36 d t_{v}$ では再び分裂している. この長周期の 変動は実時間スケールでは約 $0.1 \mathrm{~Hz}$ に相当し，これは Fig. 12 に示された低周波側のピーク周波数にほぼ一致 している.

一方，A 点渦は多少の摇動はしているもののほぼ定 常的に流下している. A 点渦の循環值は $\mathrm{F}$ 点渦の $1 / 10$ 程度であり，平均流場への影響はあまりみられない

(Fig. 7). 乱れ強度に対する影響は, 実験ではいくつか の断面で乱れ強度のわずかな増大となって現われている が，計算ではこの点は再現されていない (Fig. 8).

\section{5. モデルパラメーターを用いた流れの予測}

任意の水理条件に対するモデルパラメーターを知るこ とは，流れの予測という点において 1 つの流れに対する モデルパラメーターを得ることよりも重要であり，その モデルパラメーターの普遍性について検討することには 大きな意義があると考えられる．このような考え方に立 脚して，ここではある程度限られた Table 1 に示す範囲 内ではあるが，異なる流況に対するモデルパラメーター の普遍性について調べてみる．合流部の流れの比較を行 うためには4. に示したすべての項目について検討すべ きであるが，ここではそのうちの再循環領域の規模・形 状を逆流率によって比較・検討することとする.

ある平面形状の合流部の流況に対して, 最も影響が大 きいのは流量比 $Q_{r}$ とフルード数 $F r$ ，およびレイノル ズ数 $R e$ と考えられる. モデルパラメータ一を決定した RUN B 2 に対し, RUN B 1, B 3 は $Q_{r}$, RUN A 1, A 2, A 3 は Fr，および Re を変化させたものである. ᄀ ルード数については, RUN A 2 の $F r_{3}=0.46$ 以上にな ると水面変動か激しくなり，また用いた水平床の実験水 路では同一のアスペクト比に対してこれ以上のフルード 数の流れを得ることが困難であったため, 離散渦法の結 果と比較できるのは $F r_{3}=0.46$ をおおよその上限とす る常流範囲に限定される。なお，この条件の範囲では上 下流および支川の平均水深の水深比は高々 1.2 程度

(Table 1) であり, 平面流としての取扱いは可能と考 えられる. Fig.14に各ケースの比較を示した. Fig. 9 よ り再循環領域の規模は水面近傍の逆流率によって代表で きると考えられるので, 結果の比較には $z / H_{3}=0.9$ の 実験值を用いた。

Fig. 14(a)，（b) は異なる流量比 $Q_{r}$ に対する結果で ある. 逆流率 $I_{r}=0.5$ 以上の領域は, $Q_{r}=0.2$ の場合, Table 2 に示した $Q_{r}=0.4$ に対応するモデルパラメー ターをそのまま用いて，実験值と非常によく一致した結 果が得られている. $I_{r}=0.1$ の分布については RUN B 2 と類似した傾向がみられる， $Q_{r}=0.6$ の場合は，再循環

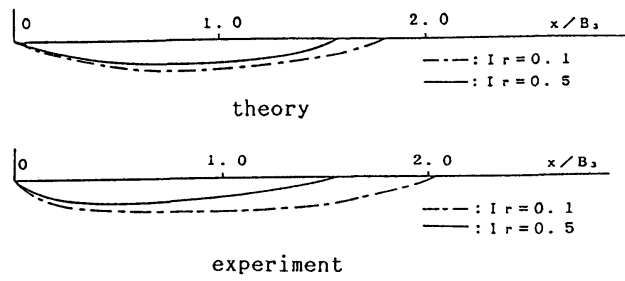

(a) Run B1

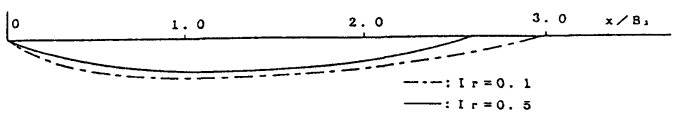

theory

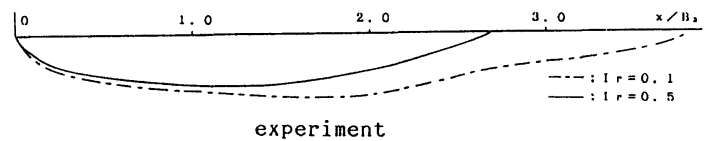

(b) Run B3

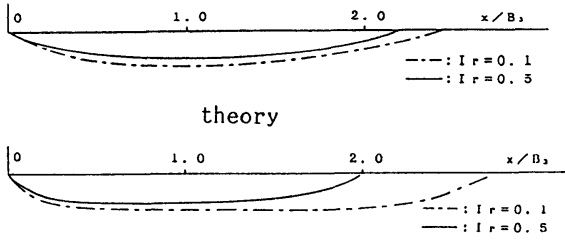

experiment

(c) Run A2

Fig. 14 Comparison of recirculating regions.

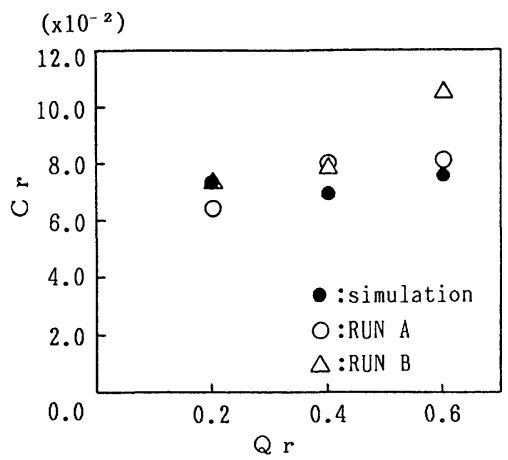

Fig. 15 Shape factors of recirculating region

領域の幅は実際よりも若干小さいが，再付着点までの長 さについては良好な結果が得られている. Fig. 14(c) は, 異なる $R e$ 数に対する結果を示しているが, $Q_{r}=0.4$ の 場合, $R e$ 数が約 2 倍程度の変化に対しては, 再循環領 域の規模には大きな変化はないことがわかった。このこ とは計算においても，示されている.

Fig. 15 には $I_{r}=0.5$ を基準とした再循環領域の形状係 数 $C_{r}(=w / L)$ の流量比 $Q_{r}$ に対する変化を示す。 $w$ は再循環領域の最大幅, $L$ は剝離点から再付着点まで の長さである.これより $C_{r}$ の計算値は $Q_{r}$ によらず， 
ほぼ一定值 $C_{r}=0.07$ であり, 再循環領域は相似形を保 つという結果が得られている.これに対し, 実験結果は, RUN B $\left(Q_{r}=0.6\right)$ を除いて計算値とよく一致している ことがわかる. RUN B $\left(Q_{r}=0.6\right)$ の場合の不一致は, 本研究の離散渦モデルでは $R e$ 数の影響を間接的に渦発 生率 $d t_{v}$ の変化, および渦糸の消去によって表わして いるだけであり，Re 数が小さい場合における水路中央 へ向かう渦の拡散を, 十分にはシミュレートできていな いことが原因と思われる. この点は粘性効果を直接的に 取り入れたさらに詳細なモデルの改良を行い, また，4. で述べたように個々の渦系の移動速度に, 水路中央へ向 かう付加的な移動速度を加えれば解消されると考えられ るが, その付加速度等については不明な点が多く, 今後 合理的な決定法を含めた検討が必要亡思われる. しかし ながら, 本研究で示したような比較的単純なモデルを用 いても, マクロ的な逆流域の予測が可能であり, 合流部 の流れのシミュレーションモデルとして十分有効である と考えられる.

\section{6. 結 論}

本研究では離散渦法を直角合流部の流れに適用し, 以 下の結論を得た。

（1） 渦糸発生率を $U_{3} d t_{v} / B_{3}=0.0889$ とし, 渦系発 生位置等のモデルパラメーターを適当に定めることによ り, 合流部の流れの平均流, 乱れ強度, および再循環領 域の規模等を再現することができた.

(2) 再循環領域内の渦群の空間的な合体・崩壊過程 についても, その低周波の非定常特性を含めて実験結果 を再現することができた。

（3）モデルパラメーターの普遍性について検討し, 少なくとも同一の平面形状, 低フルード数の合流部に対 しては，同一のモデルパラメーターを用いて，異なる流 量比, レイノルズ数における逆流域の特性をある程度,
予測することができることを明らかにした.

（4）本手法の基本流はポテンシャル流であるため, 渦群の直接的な影響が及ばない一様流領域の乱れ特性や 粘性効果が卓越する壁面近くの流れの特性に関するシ ミュレーション精度が低下するという適用上の問題点が ある.このような点に関しては, 渦糸の時間減衰や渦糸 の運動にランダムウォークを取り入れることにより，精 度を改善できると思われるのでさらに今後の検討が必要 と考える.

\section{参 考 文 献}

1）神田 徹・古川圭三 : 合流点渦領域の流れに対するVortex shedding モデル, 第 26 回水理講演会論文集, pp. $659 \sim 666,1982$.

2）永野三郎・内藤政彦・高田浩之：うず点法による長方形 柱まわりの流れの解析, 機械学会論文集 (B編), Vol. 47, No. 413, pp. 32〜43, 1981.

3）清水誠二・山口 惊 : 離散渦法による二次元衝突噴流の 数值実験, 日本機械学会論文集 (B 編), Vol. 52, No. 477, pp. 2078 2083, 1986.

4) Clements, R. R. : An inviscid model of two-dimensional vortex shedding, J. Fluid Mech., Vol.57, pp. 321 $\sim 336,1973$.

5) 巽 友正 編: 乱流現象の科学 その解明と制御, 東京大 学出版会, pp. 223 224, 1986.

6) 今井 功: 流体力学 (前編), 裳華房, 1973.

7) Leonard, A. : Vortex methods for flow simulation, J. Comp. Phys., Vol. 37, pp. 289 335, 1980.

8) Kuwahara, K. : Numerical study of flow past an inclined flat plate by an inviscid model, J. Phy. Soc. Japan, Vol. 35, pp. 1545 1551, 1973.

9) Milne-Thomson: Theoretical hydrodynamics, 5th ed., MacMillan Press Ltd., 1968.

10) Kiya, M., Sakai, K. and Arie, M. : Discrete-vortex simulation of a turbulent separation bubble, J. Fluid Mech., Vol. 120, pp. 219 244, 1982

(1988.11.2 - 受付) 